
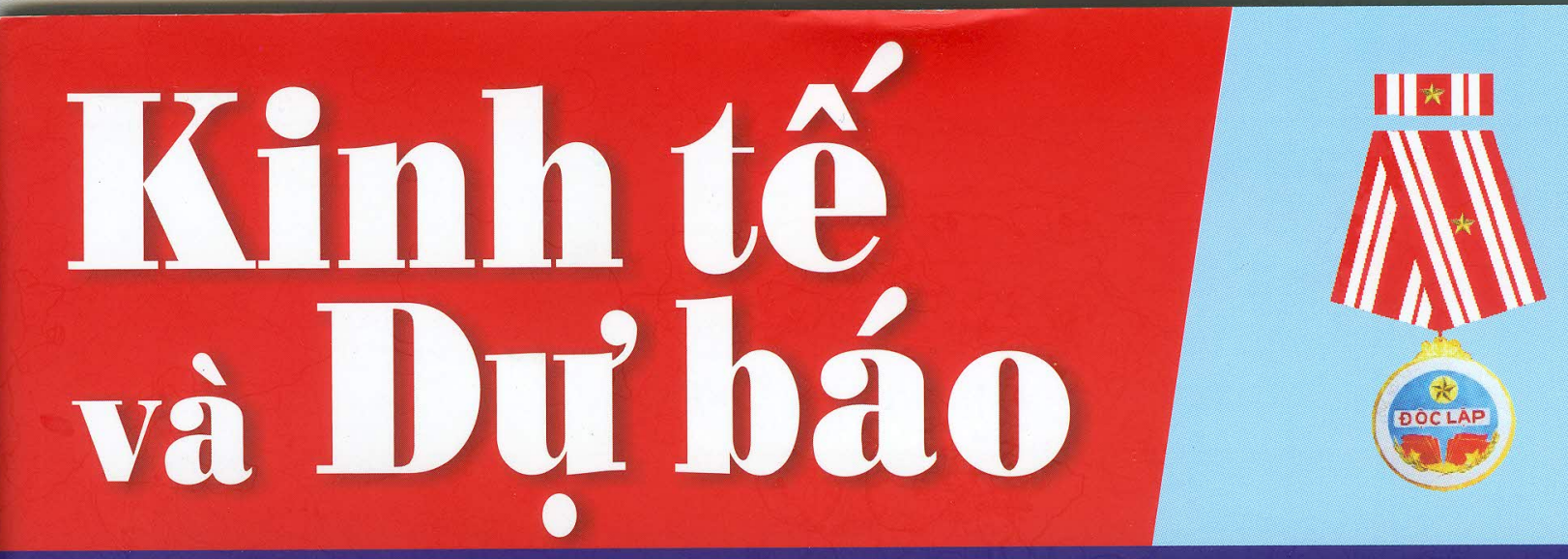

Economy\&

Forecast

Review

DOCLAP

DOCLAP

$\frac{02 / 2019}{\text { Số } 05}$

CƠ QUAN NGÔN LUẬN CỦA BỘ KẾ HOẠCH VẢ ĐẦU TỦ

ISSN 0866-7120

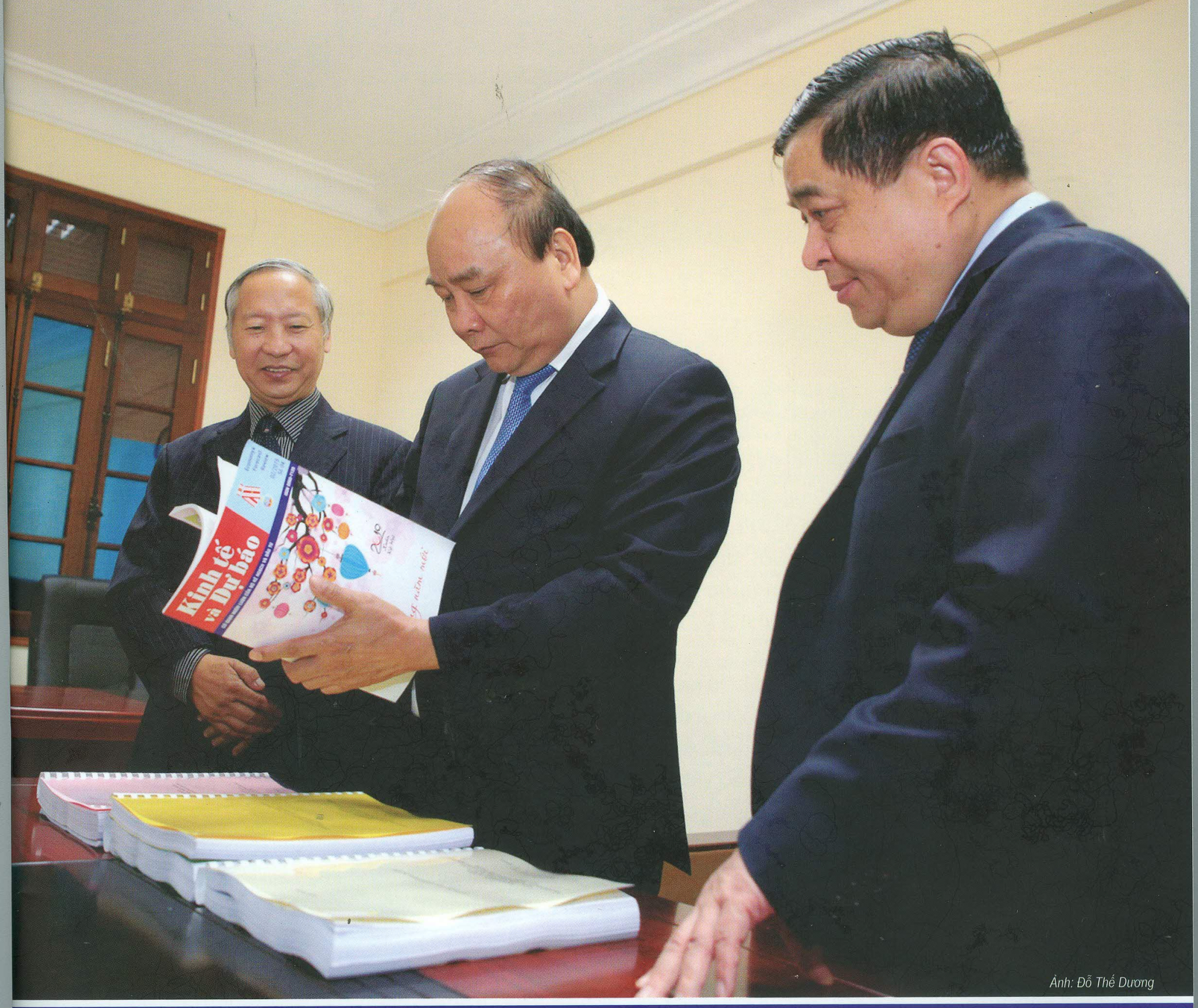

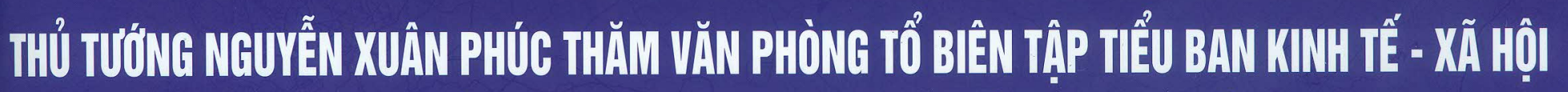

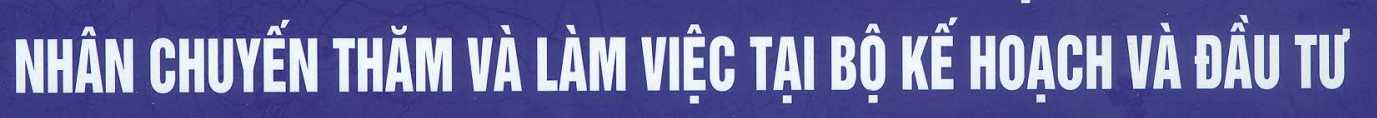
NGAYY 19/02/2019 


\section{Kinh tế và Dự báo}

ECONOMY AND FORECAST REVIEW

CO̊ QUAN NGÔN LUẬN

CƯA BÔ KẾ HOẠCH VÀ DẦU TỦ

Tổng Biên tập

PGS, TS. LÊ XUÂN ĐìNH

Phó Tổng Biên tập

ĐỖ TH! PHUOONG LAN

NGUYẼ̃N LẸ THỦY

Hội đồng Biên tập

TS. CAO VIÉ́T SINH

PGS, TS. LÊ QUỐC LÝ

PGS, TS. BÜI TẤT THÁNG

TS. NGUYỄN ĐINNH CUNG

PGS, TS. NGUYỄN HÔNNG SON

GS, TS. TRẦN THO DAT

PGS, TS. TRẦN ĐINNH THIÊN PGS, TS. NGUYẼN ĐìNH THO PGS, TS. NGUYỄN TIẾN DŨNG

TS. VUOONG QUÂN HOÀNG

Tòa soạn và trị sự

65 Văn Miếu - Đống Đa - Hà Nội

Tel: $080.43174 / 080.44474$

Fax: 024.3747.3357

Email: kinhtedubao@mpi.gov.vn

Tạp chí điện tử

http://kinhtevadubao.vn

Chi nhánh phía Nam

289 Điện Biên Phủ,

Quận 3 - TP. Hồ Chí Minh

Tel/Fax: 02839330669

Quảng cáo và phát hành

Tại tòa soạn: $080.48310 / 0905646814$

Qua mạng lưới Bưu điện Việt Nam

Giấy phép xuất bản: 115/GP-BTTTT In tại: Công ty $\mathrm{CP}$ in Công đoàn Việt Nam

Giá 19.500 đồng

\section{MỤC LỤC}

THỬ TƯớNG CHÍNH PHỦ NGUYỄN XUÂN PHÚC THĂM VÀ LÀM VIỆC Với BỘ KẾ HOACH VÀ DẦU TƯ

\& Bộ Kế hoạch và Đầu tư phải là khối óc sáng suốt tham mưu cho Chính phủ,

Thủ tướng Chính phủ trong điều hành kinh tế - xã hội của đất nước .....................................3

\& Bộ Kế hoạch và Đầu tư giữ vững ngọn cờ cải cách, luôn đi đầu trong đổi mới................ 13

Từ CHINH SÁCH DẾN CUỘC SỐNG

Nguyễn Đức Long: Những thành công trong điều hành chính sách tiền tệ năm 2018

và định hướng năm 2019 ...

Trương Minh Đức, Phạm Thị Hạnh: Thực hiện chiến lược tăng trưởng xanh

ở Việt Nam

PHÂN TÍCH - NHÂN DINH - DỰ BÁO

Ngô Thắng Lợi, Trịnh Hà Hoàng Linh: Nhìn lại sự chuyển dịch cơ cấu

ngành kinh tế Việt Nam đến năm 2018 theo quan điểm phát triển bền vững ......................26

Nguyễn Đại Lai: Thành tựu kinh tế - tài chính Việt Nam năm 2018

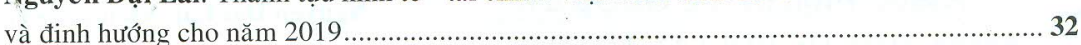

Lê Trúc Thuận: Lợi thế cạnh tranh của các ngân hàng thương mại Việt Nam ................. 35

NGHIÊN CÚO - TRAO DỐl

Hoàng Ngọc Phong: Một số vấn đề đặt ra về liên kết phát triển, quản lý khai thác,

sử dụng hợp lý tài nguyên vùng ven biển Đồng bằng sông Hồng ....................................... 39

Phạm Quốc Quyết: Xây dựng thương hiệu: "Cứu cánh" cho nông sản Việt ..................... 43

Nguyễn Tiến Phong, Phạm Bảo Dương: Một số vấn đề lý luận về phát triển

kinh tế tập thể trong xây dựng nông thôn mởi...................................................................46

Hà Nam Khánh Giao, Lê Thị Thúy Nga: Phân tích hoạt động kinh doanh

của Tập đoàn Công nghiệp Cao su Việt Nam giai đoạn 2013-2017 ................................49

Nguyễn Thị Thanh Bình: Nâng cao chất lượng nhân lực ở Tổng Công ty Thái Sơn

- Bộ Quốc phòng ....................................................................................................... 52

Đào Thị Hương: Vận dụng phương pháp xác định chi phí hiện đại

tại các doanh nghiệp sản xuất hàng may mặc khu vực phía Bắc..................................... 55

NHIN RA THẾ Giớ

Phùng Tất Hữu: Khai thác các công trình kết cấu hạ tầng nông thôn

vào phát triển kinh tế - xã hội ở một số quốc gia và gợi ý cho Việt Nam

Đỗ Kiến Vọng: Quản lý nhà nước về đấu thầu mua sắm công của Hàn Quốc

và Singapore, một số gợi ý cho Việt Nam.....

Phitsanoukone Phonevilaysack, Chansamay Denphoulouang, Bounsanong Silavy:

Giải pháp phát triển bền vững xuất khẩu điện năng của Cộng hòa Dân chủ Nhân dân Lào...

KNH TẾ NGÀNH - LÃNH THỔ

Lâm Thùy Dương: Giải pháp thu hút FDI theo hướng bền vững của tỉnh Vĩnh Phúc đến năm 2025

Phan Mạnh Cường: Thái Nguyên phát triển bền vửng các khu công nghiệp, tạo động lực đẩy mạnh công nghiệp hóa, hiện đại hóa .................................................... 72 Hoàng Minh Đẹp: Thực trạng và giải pháp phát triển kinh tế lâm nghiệp

ở tỉnh Yên Bái hiện nay...

Trần Thanh Quang: Tập trung ruộng đất để phát triển nông nghiệp công nghệ cao:

Kinh nghiệm Hà Nam, Lâm Đồng và gợi ý cho Thái Bình ............................................. 77

Lê Thị Thu Hiền, Đinh Thị Thu Hương, Lê Minh Phương: Du lịch thông minh ở tỉnh Ninh Bình: Thực trạng và giải pháp ...

Nguyễn Tử Hoài Sơn, Lê Cao Độ: Ninh Bình

- Tiềm năng và định hướng phát triển kinh tế biển ......

Phước Minh Hiệp, Lương Minh Non: Giải pháp hoàn thiện công tác quản lý thu, chi

ngân sách nhà nước tại huyện Đông Hải, tỉnh Bạc Liêu . 


\title{
Phân tích hoạt động kinh doanh của Tập đoàn Công nghiệp Cao su Việt Nam giai đoạn 2013-2017
}

HÀ NAM KHÁNH GIAO* LÊ THI THÚYY NGA**

\begin{abstract}
Ngày 05/01/2013, Thủ tướng Chính phủ ký Quyết định số 38/QĐ-TTg về việc Phê duyệt Đề án tái cơ cấu Tập đoàn Công nghiệp Cao su Việt Nam (VRG) giai đoạn 2012-2015. Thực hiện Đề án tái cơ cấu, VRG đạt được những kết quả khả quan trong hoạt động sản xuất, kinh doanh. Bài viết tiến hành phân tích thực trạng hoạt động VRG trong giai đoạn tái cơ cấu chuẩn bị thực hiện cổ phần hóa, từ năm 2013 đến 2017, từ đó đề xuất giải pháp trong thời gian tới.
\end{abstract}

\section{THỰC TRẠNG HOẠT ĐỘNG}

\section{Về doanh thu}

Giai đoạn 2013-2017, doanh thu của VRG có xu hướng giảm mạnh, nhưng biên lợi nhuận gộp của Tập đoàn vẫn duy trì tốt. Dù vậy, lợi nhuận hợp nhất vẫn tụt dốc theo giá cao su; tỷ lệ tổng nợ trên vốn chủ sở hữu của Tập đoàn giảm dần, từ $71,67 \%$ xuống còn $57,3 \%$ (tại thời điểm 31/06/2017). Các chỉ số thanh khoản tốt, cụ thể như: chỉ số thanh toán hiện hành ở mức 1,67 và chỉ số thanh toán nhanh đat 1,24.

Năm 2017, VRG ước tính hoàn thành vượt các chỉ tiêu kế hoạch (KH). Cụ thể, sản lượng cao su khai thác đạt 273.000 tấn, vượt $9 \%$ KH năm. Sản lượng cao su thu mua đạt 93.000 tấn, tiêu thụ 344.000 tấn, vượt lần lượt $30 \%$ và $11 \% \mathrm{KH}$ năm. Sản phẩm gỗ các loại đạt $1.150 .000 \mathrm{~m}^{3}$; các khu công nghiệp cho thuê được 290ha. Tổng tài sản Tập đoàn khoảng 73.000 tỷ đồng; doanh thu thuần hợp nhất 19.000 tỷ đồng, lợi nhuận sau thuế đạt khoảng 3.600 tỷ đồng, lần lượt bằng $103 \%$ và $118 \%$ mục tiêu kinh doanh. Doanh thu hợp nhất của Tập đoàn chia theo các mảng chính là cao su, gỗ, khu công nghiệp, công nghiệp cao su, trong đó, cao su chiếm $70 \%$.

\section{Về hiệu quả sử dụng vốn}

Bảng 1 cho thấy, vòng quay vốn của VRG có xu hướng giảm giảm từ năm 2013 đến năm 2016, tăng lại trong năm 2017. Số vòng quay vốn của VRG là khá thấp và thời gian quay vòng vốn là khá cao, trung bình hơn 3 năm/một vòng, cho thấy việc sử dụng vốn chưa hiệu quả của VRG. Hiệu quả sử dụng vốn trong việc tạo ra lợi nhuận cũng khá thấp, năm 2017, với 100 đồng vốn tạo ra 4,2 đồng lợi nhuận, có tăng 0,2 đồng so với năm 2016, nhưng vẫn còn rất thấp.

BẢNG 1: PHÂN TícH HIỆU QUẢ SỬ DụNG VốN CỦA VRG

\begin{tabular}{|c|c|c|c|c|c|c|c|}
\hline \multirow{2}{*}{ Chỉ tiêu } & \multirow{2}{*}{$\begin{array}{l}\text { Năm } \\
2013\end{array}$} & \multirow{2}{*}{$\begin{array}{l}\text { Năm } \\
2014\end{array}$} & \multirow{2}{*}{$\begin{array}{l}\text { Năm } \\
2015\end{array}$} & \multirow{2}{*}{$\begin{array}{l}\text { Năm } \\
2016\end{array}$} & \multirow{2}{*}{$\begin{array}{l}\text { Năm } \\
2017\end{array}$} & \multicolumn{2}{|c|}{$\begin{array}{l}\text { Chênh lệch } \\
\text { 2017/2016 }\end{array}$} \\
\hline & & & & & & $\begin{array}{l}\text { Tuyêt } \\
\text { đối }\end{array}$ & $\begin{array}{l}\text { Tỷ lệ } \\
(\%)\end{array}$ \\
\hline 1. Doanh thu thuần & 21.463 & 17.267 & 15.116 & 15.576 & 18.260 & $2.683,93$ & 17,23 \\
\hline 2. Lợi nhuận sau thuế & 3.790 & 2.297 & 1.935 & 2.797 & 3.060 & 263,40 & 9,42 \\
\hline 3. Tổng vốn & 65.838 & 63.469 & 66.838 & 69.803 & 73.120 & $3.317,44$ & 4,75 \\
\hline 4. Số vòng quay vốn & 0,326 & 0,272 & 0,226 & 0,223 & 0,250 & 0,03 & 11,91 \\
\hline 5. Số ngày luân chuyển (ngày) & 117 & 98 & 81 & 80 & 90 & 9,57 & 11,91 \\
\hline 6. Hiệu quả sử dụng vốn & 0,058 & 0,036 & 0,029 & 0,040 & 0,042 & 0,00 & 4,45 \\
\hline 7. Hệ số đảm nhiệm vốn & 3,07 & 3,68 & 4,42 & 4,48 & 4,00 & $-0,48$ & $-10,64$ \\
\hline 8. Lợi nhuận sau thuế & 3.790 & 2.297 & 1.935 & 2.797 & 3.060 & 263 & 9,0 \\
\hline 9. Vốn chủ sở hữu & 38.350 & 38.285 & 43.587 & 45.202 & 46.250 & 1.048 & 2,0 \\
\hline 10. ROS $(\%)$ & 17,66 & 13,31 & 12,80 & 17,95 & 16,76 & & 5,2 \\
\hline 11. ROA $(\%)$ & 5,76 & 3,62 & 2,90 & 4,01 & 4,18 & & 1,1 \\
\hline 12. ROE (\%) & 9,88 & 6,00 & 4,44 & 6,19 & 6,62 & & 1,7 \\
\hline
\end{tabular}

Nguồn: Tập đoàn Công nghiệp Cao su Việt Nam (2014-2018)

"PGS, TS., Trường Đại học Tài chính - Marketing

** Công ty TNHH Transtech Việt Nam । Email: bella.kyungdong@gmail.com 
BẢNG 2: HIÊU SUẤT SỬ DỤNG TÀI SẢN CỦA VRG GIAI DOẠN 2013-2017

Đơn vị: Tỷ đồng

\begin{tabular}{|l|r|r|r|r|r|}
\hline \multicolumn{1}{|c|}{ Chỉ tiêu } & Năm & Năm & Năm & Năm & Năm \\
$\mathbf{2 0 1 3}$ & $\mathbf{2 0 1 4}$ & $\mathbf{2 0 1 5}$ & $\mathbf{2 0 1 7}$ \\
\hline 1. Doanh thu thuần & 21.463 & 17.267 & 15.116 & 15.576 & 18.260 \\
\hline 3. Hàng tồn kho & 1.852 & 2.106 & 2.933 & 2.601 & 4.852 \\
\hline 3. Tổng tài sản & 65.838 & 63.469 & 66.838 & 69.803 & 73.120 \\
\hline 4. TSCĐ & 13.350 & 13.698 & 14.025 & 16.870 & 17.139 \\
\hline 5. Số vòng quay tài sản & 0,33 & 0,27 & 0,23 & 0,22 & 0,25 \\
\hline 6.Sức sản xuất của TSCĐ & 0,62 & 0,79 & 0,93 & 1,08 & 0,94 \\
\hline 7. Hê̂ số sử dụng tài sản & 3,07 & 3,68 & 4,42 & 4,48 & 4,00 \\
\hline 8. Số vòng quay hàng tồn kho & 11,59 & 8,20 & 5,15 & 5,99 & 3,76 \\
\hline 9. Thời gian quay vòng hàng tồn kho & 31 & 44 & 70 & 60 & 96 \\
\hline
\end{tabular}

Nquồn: Tâp đoàn Công nghiệp Cao'su Việt Nam (2014-2018)

BẢNG 3: TRINHH ĐỘ CÁN Bộ CÔNG NHÂN VIÊN VRG GIAI DOẠN 2013-2017

Đơn vị: Người

\begin{tabular}{|l|r|r|r|r|r|}
\hline \multicolumn{1}{|c|}{ Chỉ tiêu } & $\begin{array}{c}\text { Năm } \\
\mathbf{2 0 1 3}\end{array}$ & $\begin{array}{r}\text { Năm } \\
\mathbf{2 0 1 4}\end{array}$ & $\begin{array}{c}\text { Năm } \\
\mathbf{2 0 1 5}\end{array}$ & $\begin{array}{c}\text { Năm } \\
\mathbf{2 0 1 6}\end{array}$ & $\begin{array}{c}\text { Năm } \\
\mathbf{2 0 1 7}\end{array}$ \\
\hline Trên đại học & $\mathbf{7 8 2}$ & 890 & 978 & 1.174 & 1.225 \\
\hline Đại học & 4.560 & 5.970 & 6.875 & 7.156 & 7.980 \\
\hline Cao đẳng & 3.256 & 3.756 & 3.872 & 4.125 & 4.597 \\
\hline Trung cấp & 15.123 & 16.740 & 17.850 & 18.793 & 19.547 \\
\hline Lao động phổ thông & 63.702 & 58.798 & 56.946 & 56.662 & 54.851 \\
\hline Tổng lao động & 87.423 & 86.154 & 86.521 & 87.910 & 88.200 \\
\hline Doanh thu thuần (tỷ đồng) & 21.463 & 17.267 & 15.116 & 15.576 & 18.260 \\
\hline Lợi nhuận ròng & 4.791 & 2.904 & 2.446 & 3.535 & 3.868 \\
\hline Lợi nhuận bình quân 1 lao động & 0,055 & 0,034 & 0,028 & 0,040 & 0,044 \\
\hline Doanh thu bình quân 1 lao động & 0,246 & 0,200 & 0,175 & 0,177 & 0,207 \\
\hline
\end{tabular}

BẢNG 4: CHỈ TIÊU ĐÁNH GIÁ HIỆ̃ QUẢ XÃ HộI CỦA VRG

Đơn vị: Tỷ đồng

\begin{tabular}{|l|r|r|r|r|r|}
\hline \multicolumn{1}{|c|}{ Chỉ tiêu } & Năm 2013 & Năm 2014 & Năm 2015 & Năm 2016 & Năm 2017 \\
\hline 1. Lợi nhuận trước thuế & 4.987 & 2.987 & 2.473 & 3.270 & 3.756 \\
\hline 2. Nộp NSNN & 1.197 & 690 & 538 & 473 & 696 \\
\hline 3. Tổng lao động (Người) & 87.423 & 86.154 & 86.521 & 87.910 & 88.200 \\
\hline 4. Thu nhập bình quân (Tr.đ) & 4,25 & 4,85 & 5,20 & 5,75 & 6,50 \\
\hline
\end{tabular}

Nguồn: Tập doàn Công nghiệp Cao su Việt Nam (2014-2018)

Hệ số đảm nhiệm vốn của VRG cũng khá cao qua các năm, trung bình là trên 3,5 , nghĩa là phải dùng tới 3,5 đồng vốn mới tạo ra được 1 đồng doanh thu. Tuy nhiên, sang năm 2017, hệ số này có giảm nhẹ 0,48 còn lai là 3,02.

Hêe số ROS (Return on sales - Tỷ số lợi nhuận trên doanh thu) của VRG tăng giảm không đều trong giai đoạn 2013-2017. Năm 2013 là 17,66\%, nghĩa là 100 đồng doanh thu thuần đem lại 17,66 đồng lợi nhuận sau thuế; năm 2017, ROS của VRG giảm nhẹ 1,2\% so với năm 2016, nguyên nhân là tốc độ tăng doanh thu nhỏ hơn tốc độ tăng của chi phí.

ROA (Return on total assets - Tỷ số lợi nhuận ròng trên tài sản) năm 2014 giảm so với năm 2013 là 2,1\%, nghĩa là nếu trong năm 2013 cứ 100 đồng tài sản tạo ra
5,76 đồng lợi nhuận sau thuế, sang năm 2014, con số này chỉ đạt 3,26 đồng. Năm 2017, ROA của VRG tăng nhẹ lên, đạt $4,18 \%$, tương ứng tăng là $0,2 \%$ so với năm 2016. Như vậy, VRG vẫn chưa sử dụng thật sự hiệu quả tài sản trong việc tạo ra lợi nhuận, tỷ suất sinh lời của tài sản là khá thấp so với các doanh nghiệp khác trong ngành ở mức trung bình là $5 \%$.

Tương tự, ROE (Return on equity - Lợi nhuận trên vốn chủ sở hữu) của VRG giảm sút từ năm 2013 đến 2015, tăng lên từ năm 2016 và 2017 . ROE của VRG khá thấp so với trung bình ngành cao su là $9,8 \%$.

Bảng 2 cho thấy, số vòng quay tài sản giai đoạn 2013-2017 là khá thấp, trung bình chỉ đạt 0,25 vòng, nghĩa là trong 1 năm, tài sản chưa luân chuyển hết 1 vòng. Hệ số sử dụng tài sản giai đoạn 2013-2017 là khá cao, trung bình hơn 4, là chưa tốt. Sức sản xuất tài sản cố định khá thấp trong giai đoạn 2013-2017, cụ thể năm 2014 cần tới 0,79 đồng tài sản cố định thì mới tạo ra được 1 đồng doanh thu, năm 2017, thì chỉ số này mới giảm xuống còn 0,94 tương ứng giảm là 0,14 so với năm 2016. Số vòng quay hàng tồn kho là khá cao, năm 2014 hàng tồn kho chỉ quay được 8,2 vòng thấp hơn năm 2013, năm 2017, thì chỉ số này giảm xuống còn 3,76 .

\section{Về hiệu quả sử dụng lao động}

Bảng 3 cho thấy, số lao động có trình đô trên đại học có xu hướng tăng dần qua các năm, nhưng cũng mới chỉ chiếm tỷ trọng khoảng $1 \%$ trong VRG. Số lượng công nhân kỹ thuật đã qua đào tạo chiếm $88,5 \%$, hàng năm VRG đều có kế hoạch bổ sung đội ngũ công nhân đã qua đào tạo để nâng cao chất lượng.

Bảng 3 cũng cho thấy, lợi nhuận bình quân 1 lao động giai đoạn 2013-2017 là khá thấp, trung bình hơn 40 triệu đồng/ lao động/năm. Điều này cho thấy, hiệu quả sử dụng lao động của Tập đoàn trong việc tạo ra lợi nhuận là chưa tốt. Doanh thu bình quân 1 lao động giai đoạn 20132017 là khá thấp, trung bình hơn 180 triệu đồng/lao động/năm.

\section{Về hiệu quả chính trị - xã hội}

VRG có mức đóng góp cho ngân sách nhà nước rất cao. Mặc dù có giảm dần qua các năm 2014-2016, nhưng đến năm 2017 đã tăng lên mức 696 tỷ đồng (Bảng 4). VRG cũng luôn nỗ lực không ngừng trong việc nâng cao đời sống cho người lao động, mức lương của người lao động được tăng qua các năm, đến năm 2017, 
mức lương trung bình người lao động là 6,5 triệu đồng tương ứng tăng là 0,75 triệu đồng so với năm 2016.

Một vài đánh giá chung

Kết quả đạt được

Tập đoàn đã tái cấu trúc các công ty con trực thuộc và tiến hành thoái vốn và cổ phần hóa nhằm cấu trúc lại doanh nghiệp. Doanh thu của VRG trong năm 2017 đã có dấu hiệu tăng trở lại với tốc độ tăng trưởng doanh thu trên 17\%. Các chỉ tiêu về lợi nhuận, tỷ suất lợi nhuận có dấu hiệu tốt trong giai đoạn 2015-2017, mức tăng trên $10 \%$ mỗi năm, khá tốt so với các doanh nghiệp trong cùng ngành. VRG cũng không ngừng có các chính sách nâng cao đời sống người lao động về sức khỏe và thu nhập.

Han chế, tồn tại

Tất cả các chỉ tiêu hiệu quả sư dụng vốn đều thấp so với trung bình ngành, mặc dù đã có dấu hiệu tăng trưởng tốt trong 2 năm 2016-2017. Thêm vào đó, VRG còn hạn chế về chất lượng của nguồn nhân lực.

Nguyên nhân hạn chế

Các hạn chế của VRG có nguyên nhân, như: (1) Năng lực quản trị của cán bộ trong VRG còn hạn chế; (2) VRG chưa có các biện pháp thu hồi công nợ ngắn hạn hiệu quả; (3) Công tác đào tạo, tuyển dụng, đãi ngộ nhân lực của VRG còn nhiều hạn chế; (4) Vai trò của cổ đông sau khi cổ phần hóa vẫn chưa được phát huy đúng mức.

\section{MộT SỐ GIẢl PHÁP CẦN THỰC HIỆN}

\section{Thứ nhất, nâng cao năng lực quản trị sau cổ phần hóa \\ VRG cần thực hiện việc tách biệt chức năng chủ sở hữu nhà nước với chức năng quản lý nhà nước, thông qua hình thành tổ chức chuyên trách thực hiện quyền và nghĩa vụ chủ sở hữu vốn nhà nước đầu tư (Ủy ban Quản lý vốn nhà nước tại doanh nghiệp). VRG vẫn cần xây dựng}

BẢNG 5: ĐỀ XUẤT KẾ HOACH THU HỒI NỢ QUÁ HAN CHO VRG

Đơn vị: Tỷ đồng

\begin{tabular}{|c|l|r|r|r|}
\hline STT & \multicolumn{1}{|c|}{ Chỉ tiêu } & $\begin{array}{r}\text { Năm } \\
\mathbf{2 0 1 9}\end{array}$ & $\begin{array}{c}\text { Năm } \\
\mathbf{2 0 2 0}\end{array}$ & $\begin{array}{c}\text { Năm } \\
\mathbf{2 0 2 1}\end{array}$ \\
\hline 1 & Công ty TNHH Đinh Huy & 1,050 & 0,750 & 0,406 \\
\hline 2 & Công ty Cổ phần Chứng khoán Delta & 2,200 & 2,500 & 1,284 \\
\hline 3 & Công ty Kinh doanh hàng xuất khẩu Quang Đức & 1,300 & 1,230 & 1,404 \\
\hline 4 & Công ty Cổ phần Cao su miền Trung & 0,650 & 0,350 & 0,129 \\
\hline 5 & Công ty Cổ phần Đầu tư xây dựng Cao su & 5,500 & 3,280 & 2,686 \\
\hline 6 & Phải thu khách hàng khác & 21,500 & 15,500 & 13,840 \\
\hline 7 & Cộng tổng & $\mathbf{3 2 , 2 0 0}$ & $\mathbf{2 3 , 6 1 0}$ & $\mathbf{1 9 , 7 4 9}$ \\
\hline
\end{tabular}

Nguồn: Đề xuất của nhóm nghiên cứu dựa trên báo cáo tài chính của VRG

hệ thống quản trị tiệm cận thông lệ quốc tế, như của OECD. Cần nâng cao tính độc lập, chuyên nghiệp và năng lực chuyên môn của Ban Kiểm soát.

Thử hai, tăng cường hiệu quả sử dụng vốn sau cồ phần hóa

VRG cần thu các khoản nợ đã quá hạn của các doanh nghiệp sau theo kế hoạch được nếu trong Bảng 5.

VRG cần có biện pháp thu hồi công nợ một cách triệt để: (i) Tạm thời dừng cung cấp sản phẩm; (ii) Gửi văn bản đề nghị yêu cầu trả nợ; (iii) Thu hồi hàng hóa trong kho; (iv) Gửi đơn kiến nghị nhờ cơ quan có thẩm quyền giải quyết; (v) Lập kế hoạch và theo dõi sát sao các khoản nợ ngắn hạn.

Để nâng cao hiệu quả sử dụng tài sản dài hạn, VRG cần tập trung vào việc nâng cao hiệu quả của đầu tư tài chính, VRG cần thu hồi công nợ dài hạn của các doanh nghiệp.

Thứ ba, nâng cao chất lượng nguồn nhân lực sau cổ phần hóa

VRG cần: Điều chuyển lao động hợp lý; Nâng cao trình độ cho cán bộ công nhân viền và người lao động. Theo đó, cần nâng cao tay nghề, ý thức cho đội ngũ công nhân trực tiếp sản xuất; phải thường xuyên đào tạo nguồn nhân lực, tổ chức các khóa huấn luyện, trao đổi kinh nghiệm về công tác quản lý chất lượng giữa các công ty thành viên. Mở thêm các khóa bồi dưỡng chuyên môn nghiệp vụ cho cán bộ làm công tác quản lý chất lượng; Tổ chức kiểm tra chéo giữa các phòng kiểm phẩm để đảm bảo độ tin cậy và nâng cao tay nghề, trau dồi kinh nghiệm cho cán bộ làm công tác chất lượng.

\section{TÀI LIỆU THAM KHẢO}

1. Thủ tướng Chính phủ (2006). Quyết định số 249/2006/QD-TTg, ngày 30/10/2006 về việc thành lạp Công ty me - Tập đoàn Công nghiệp Cao su Việt Nam

2. Thủ tướng Chính phủ (2013). Quyết định số38/QD-TTg, ngày 05/01/2013 phê duyệt Đề án tái cơ cấu Tập đoàn Công nghiệp Cao su Việt Nam giai đoạn 2012-2015

3. Tập đoàn Công nghiệp Cao su Việt Nam (2014-2018). Báo cáo tài chính từ năm 2013 đến 2017

4. Tập đoàn Công nghiệp Cao su Việt Nam (2013-2017). Báo cáo thường niên từ năm 2013 đến 2017 